\title{
Investigation on the Needs of Preoperative Health Education of Parents, Whose Children Undergoing Day Surgery
}

\author{
Rong-ji LIAO ( $\sim 64969970 @ q q . c o m$ ) \\ Nanchang University - Qianhu Campus: Nanchang University \\ Mei-xue ZHANG \\ Nanchang University - Qianhu Campus: Nanchang University
}

\section{Research}

Keywords: Day surgery, Parents, Preoperative health education, Investigation

Posted Date: January 3rd, 2022

DOI: https://doi.org/10.21203/rs.3.rs-1191742/v1

License: (c) (i) This work is licensed under a Creative Commons Attribution 4.0 International License.

Read Full License 


\section{Abstract}

\section{Background}

To explore the needs of preoperative health education of parents $₫$ whose children undergoing day surgery, and to provide reference for nurses to carry out health education.

\section{Methods}

The parents whose children undergoing day surgery in Guangzhou Women and Children's medical center from January 2021 to February 2021 were selected as the research objects. The needs of parents for preoperative health education were investigated by questionnaire, and the needs and satisfaction of parents for the timing, content, ways and push methods of preoperative health education were observed.

\section{Results}

591 questionnaires were distributed and 578 were recovered, with a recovery rate of $97.80 \%$. The results showed that the parents had the highest demand for preoperative health education when they made an appointment for day surgery. The most desired content of health education was admission procedure, and the most desired way to receive health education was through video. The most acceptable push mode was through WeChat official account. Parents' satisfaction with the current health education was $94.64 \%$.

\section{Conclusions}

The content of preoperative health education should be formulated according to the needs of parents, whose children undergoing day surgery. The time of providing health education should be moved forward. Health education videos should be given first, combined with a variety of health education methods, and health education videos should be pushed through WeChat official account or WeChat video number, so as to ensure the smooth development of children's day surgery and enhanced recovery after surgery.

\section{Background}

Day surgery refers to a kind of operation mode in which patients with clear clinical diagnosis, complete planned admission, operation, short observation after operation and discharge within 24 hours $^{[1]}$. Day surgery can obviously shorten the hospitalization time, speed up the bed turnover rate and reduce medical expenses ${ }^{[2,3]}$, but the direct care for patients is reduced, and the preoperative preparation and postoperative care are in the family or community hospital, which makes patients face more severe psychological stress ${ }^{[4]}$. According to the study ${ }^{[5]}, 76.7 \%$ of the patients suffered from lack of perioperative knowledge and information, excessive anxiety before operation, which affected the progress and effect of the operation, and the high rate of temporary cancellation of the operation, resulting in disorder of the 
scheduled operation and loss of manpower, material resources and time. Therefore, in the process of daytime medical service, perioperative health education is particularly important ${ }^{[6]}$, but the rhythm of "short, flat and fast" in day surgery conflicts with the requirements of "all-round, steady and detailed" in health education ${ }^{[7]}$, especially in pediatric day surgery, the timing, content, approach and push mode of preoperative health education will affect the effect of health education, thus affecting the operation process and postoperative rehabilitation. At present, there is little research on preoperative health education for pediatric day surgery patients. In this study, the self-designed questionnaire was used to investigate the needs of preoperative health education of parents, whose children undergoing day surgery, and to provide more suitable preoperative health education programs for children, so as to ensure the smooth implementation of day surgery and enhanced recovery after surgery.

\section{Methods}

This study has been approved by the Medical Ethics Committee, and the informed consent form has been signed with all patients.

\section{General Information}

A total of 591 parents of children who underwent day surgery in Guangzhou Women and Children's Medical Center from January 1, 2021 to February 28, 2021 were selected to conduct a questionnaire

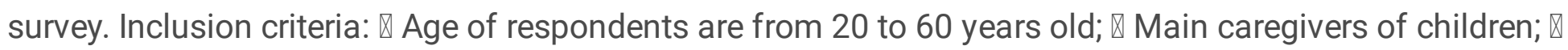
Clear consciousness and normal communication skills; $₫$ Knowing and willing to participate in this survey. Exclusion criteria: $\otimes$ Those with a previous history of mental illness; $\otimes$ Those who have experienced major stress events recently.

\section{Survey Methods}

The survey tool is a self-made questionnaire on the needs of preoperative health education of parents, whose children undergoing day surgery, which was revised repeatedly after being reviewed by relevant nursing experts on the basis of a large number of documents and materials consulted by researchers. The main contents of the questionnaire include: $\triangle$ The order of health education needs of parents,

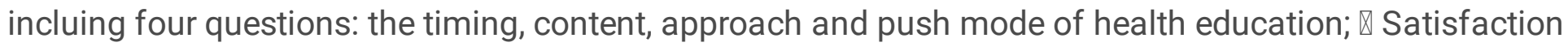
of parents with current health education and suggestions. The questionnaire is jointly distributed by the team members, and the respondents are collected in time after filling out. A total of 591 questionnaires were distributed in this survey, and 578 were recovered, with a recovery rate of $97.80 \%$.

\section{The Statistical Method}


The questionnaire adopts ranking questions, which reflects the comprehensive ranking of options. The higher the score, the higher the comprehensive ranking. The calculation method is: the average comprehensive score of options $=(\sigma$ frequency $\times$ weight $) /$ the number of people who fill in this question, and the weight is determined by the position where the options are arranged.

\section{Results}

See the following table (Table 1) for the timing, contents, ways and push ways of health education for parents, whose children undergoing day surgery. 
Table 1

Investigation on the needs of preoperative health education of parents, whose children undergoing day surgery

\begin{tabular}{|c|c|c|}
\hline Survey items & Options & Score \\
\hline \multirow{5}{*}{$\begin{array}{l}\text { Health education } \\
\text { opportunity }\end{array}$} & On the appointment of day surgery & 3.2 \\
\hline & Before preoperative examination & 1.92 \\
\hline & The day before admission & 1.7 \\
\hline & After seeing the doctor & 1.18 \\
\hline & On the day of admission & 0.93 \\
\hline \multirow{7}{*}{$\begin{array}{l}\text { Health education } \\
\text { content }\end{array}$} & Admission procedure & 5.52 \\
\hline & Precautions before operation & 5.36 \\
\hline & About the operation & 3.98 \\
\hline & Preoperative examination guidelines & 3.13 \\
\hline & $\begin{array}{l}\text { Reimbursement process of surgical expenses, medical insurance or } \\
\text { commercial insurance }\end{array}$ & 2.53 \\
\hline & Discharge process & 1.57 \\
\hline & Ward environment & 1.19 \\
\hline \multirow{5}{*}{$\begin{array}{l}\text { Health education } \\
\text { approach }\end{array}$} & Video & 3.77 \\
\hline & Health education manual & 2.72 \\
\hline & Education by nurse & 1.89 \\
\hline & Comics & 1.25 \\
\hline & Pictures & 1.18 \\
\hline \multirow{4}{*}{$\begin{array}{l}\text { Health education } \\
\text { push mode }\end{array}$} & WeChat official account & 4.92 \\
\hline & WeChat number & 2.17 \\
\hline & SMS & 1.67 \\
\hline & Tik Tok & 0.57 \\
\hline
\end{tabular}

According to the survey, parents whose children underwent day surgery had the highest demand for preoperative health education when they made an appointment for day surgery. At this time, the most desired content of health education was the admission procedure, the most desired way to receive health education was through video, and the most acceptable push mode was through WeChat official account. 
In the 578 questionnaires, 547 parents checked "satisfied" and 31 parents checked "need to improve", with a satisfaction rate of $94.64 \% .5 .36 \%$ parents of think that there was too little health education before children underwent day surgery, and various procedures were insufficient. Surgical precautions should be more detailed, and follow-up procedures should be informed when seen the doctors. Health education were not pushed in a timely manner, oral narration is too much to remember. The speed of the nurse's education suggested slowing down and being more patient.

\section{Discussion}

\section{Health education before pediatric day surgery should be moved forward}

Preoperative health education is an important link to improve perioperative nursing quality by integrating medical, biological, psychological and social knowledge ${ }^{[8]}$, and its effect and quality are one of the important factors determining surgical safety. On the day of admission, patients have only a short preparation time before surgery, the large amount of information transmitted by the surgeon, anesthesiologist, operating room nurse and day ward nurse will exceed the short-term memory capacity of parents, whose children undergoing day surgery, and also will reduce the effect of health education. In this study, parents' demand for health education ranked first when they made an appointment for day surgery. Education at this time can help parents have better operation cognition and psychological preparation, and reduce the no-show rate of day surgery, preoperative anxiety and postoperative complications $^{[9]}$. Therefore, health education before pediatric day surgery should be moved forward, which can be moved forward to the appointment of day surgery, so as to increase the digestion time of parents about day surgery related knowledge, and relieve their tension and anxiety ${ }^{[10]}$.

The content of preoperative health education for pediatric day surgery should be based on the needs of caregivers of children.

Day surgery is different from in-patient surgery. The hospitalization time of day surgery is short. Compared with in-patient surgery patients, patients with day surgery receive less direct medical care ${ }^{[11]}$. Patients and their caregivers need to undertake most of the preoperative preparation work completed by nurses. Therefore, preoperative health education should be targeted based on the needs of caregivers of children. In this study, the content of health education that parents want most before operation is the admission procedure, followed by the precautions before day surgery, which are also the contents that easily overlooked by nurses in the implementation of health education. Therefore, based on the needs of caregivers of children, constantly updating and optimizing the preoperative health education content of day surgery can ensure the smooth development of day surgery, reduce the temporary cancellation rate of day surgery and reduce the waste of manpower, material resources and time.

The ways of health education for pediatric day surgery should be diversified, mainly video health education, combined with health education manuals and nurses' explanations. 
Many people can only remember $50 \%$ of the information they just listened to. For the character content sent by SMS, it needs further processing by the brain, and the information output efficiency is low and it is not easy to get feedback. Video contains images and audio, which can express what video producers want to express or present in the way that is closest to people's understanding of the surrounding environment at the beginning. The biggest feature and advantage of video in communication mode is directness and high efficiency. In this study, the way of health education by video ranks first, which shows that the video education mode is easy to be accepted by people. In the health education of pediatric day surgery, video education should be given priority to, combined with the health education manual and nurse's explanation ${ }^{[12]}$, so that preoperative education can be smoothly and efficiently carried out. In the research of Lu Chaorong ${ }^{[13]}$, Zhu Zhangling ${ }^{[14]}$, it is also considered that the video education mode is superior to the traditional preoperative education mode.

\section{The push mode of health education content of pediatric day surgery should be convenient and easy to obtain, and patients can watch and give feedback anytime, anywhere.}

This survey shows that parents of children tend to use WeChat official account as the first choice for health education. WeChat is a convenient and accessible platform, and patients can receive health education anytime and anywhere by watching the push content of WeChat official account. The latest data of WeChat shows that every day, 1.09 billion users open WeChat, 780 million users enter the circle of friends and 360 million users read WeChat official account's articles. WeChat has become a "lifestyle" for people. People have taken WeChat official account as one of the main ways to get information ${ }^{[15]}$. The preoperative health education of pediatric day surgery should not be left behind in this new media wave. We should take WeChat official account and WeChat video number as the platform of health education, and strive to build a brand of pediatric day surgery health education service.

\section{Conclusions}

In the conclusion, the implementation of preoperative health education for pediatric day surgery should be moved forward to the appointment of day surgery, and the health education content should be formulated based on the needs of the child caregivers, mainly by video education, combined with the health education manual and nurses' explanation, and through the push and dissemination of WeChat official account and WeChat video number. In order to reduce the perioperative anxiety of the child caregivers, so as to ensure the smooth development of the child day surgery and enhanced recovery after surgery.

\section{Declarations}

\section{Ethics approval and consent to participate}

This study was approved by Guangzhou Women and Children's Medical Center's Scientific Research and Ethics Committee. Signed informed consent was obtained from the parents or legal guardians before 
inclusion in the study.

\section{Consent for publication}

Not applicable. The study does not contain identifiable details or images from any individual person.

\section{Availability of data and materials}

Information available under request.

\section{Competing interests}

The authors declare that they have no competing interests.

\section{Funding}

No funding.

\section{Authors' contributions}

Not applicable.

\section{Acknowledgements}

We are grateful to all the nurses of Day Surgery Center, and all the personnel of the surgical area for their care and professionalism with patients.

\section{Authors' information (optional)}

Rong-ji LIAO, work in operation room in Guangzhou Women and Children's Medical Center as a nurse. The Email address is644969970@qq.com.

\section{References}

1. Dongxu L. Chen Liumei. et al. Discussion on the centralized management mode of pediatric day surgery. Chinese Journal of Pediatric Surgery. 2020;41(08):698-703.

2. Cabric E, Zvornicanin J, Jusufovic V. The safety and efficacy of day care cataract surgery. Med Arch. 2014;68(2):117-20.

3. Ji Wu L, Yaping, et al. Current situation and prospect of daytime surgery in China. Chinese Journal of Practical Surgery. 2020;40(2):199-202.

4. Rajala M, Kaakinen P, Fordell M, Kääriäinen M. The Quality of Patient Education in Day Surgery by Adult Patients. J Perianesth Nurs. 2018;33(2):177-87.

5. Zhang Y. Dai Yan, et al. Reason analysis and countermeasures of temporary cancellation of day surgery. West China Medical Science. 2014;29(10):1943-5. 
6. Wongkietkachorn A, Wongkietkachorn N, Rhunsiri P. Preoperative Needs-Based Education to Reduce Anxiety, Increase Satisfaction, and Decrease Time Spent in Day Surgery: A Randomized Controlled Trial. World J Surg. 2018;42(3):666-74.

7. Gu Chunhong Z, Jiahuan, et al. The influence of diversified education mode on the health awareness and satisfaction of patients undergoing day surgery in ophthalmology. Chinese Journal of Modern Nursing. 2019. (19): 2391-2393.

8. Ji Xuejing. Effectiveness of health education path in nursing quality of elective cesarean section. Management of Chinese health standards. 2015. 6(21): 158-159.

9. Barbier D, N'Dele D, Bennis M, Thevenin-Lemoine C, De Gauzy JS, Accadbled F. Day surgery for anterior cruciate ligament reconstruction in children: a prospective study on feasibility and satisfaction. J Child Orthop. 2019;13(1):100-6.

10. Zhou J. Huang, Lingzhi, et al. Research on the status quo and influencing factors of health education of cardiac rehabilitation carried out by nurses in cardiovascular medicine department. Contemporary nurses. 2019;26(8):167-9.

11. Ren Jie L. Hong, et al. Brief introduction of day surgery management in ophthalmology in China. Chinese Nursing Management. 2014;14(04):440-1.

12. Wu Zhi Z, Xuebing, et al. Investigation of parents' health needs before children's day surgery. Qilu Journal of Nursing. 2019;25(18):59-61.

13. Lu Chaorong T, Siyuan, et al. Effect of micro-video preoperative visit on anxiety of patients and research. 2017. 14(15): 80-81.

14. Zhu Zhangling. Application of video education in day cataract surgery patients. Journal of Nursing. 2019;26(9):74-6.

15. Li Rong. Viewing the service brand building of university library from WeChat official account. New Century Library. 2018. (10): 93-97. 